Research article Open Access

\title{
A common missense variant in BRCA2 predisposes to early onset breast cancer
}

\author{
Bohdan Górski ${ }^{1}$, Steven A Narod ${ }^{2}$ and Jan Lubiński ${ }^{1}$
}

\author{
1Department of Genetics and Pathology, International Hereditary Cancer Center, Pomeranian Medical University, Szczecin, Poland \\ ${ }^{2}$ Centre for Research on Women's Health, University of Toronto, Canada \\ Corresponding author: Steven A Narod, steven.narod@sw.ca
}

Received: 17 Mar 2005 Revisions requested: 15 Apr 2005 Revisions received: 20 Sep 2005 Accepted: 28 Sep 2005 Published: 24 Oct 2005

Breast Cancer Research 2005, 7:R1023-R1027 (DOI 10.1186/bcr1338)

This article is online at: http://breast-cancer-research.com/content/7/6/R1023

(C) 2005 Górski et al.; licensee BioMed Central Ltd.

This is an Open Access article distributed under the terms of the Creative Commons Attribution License (http://creativecommons.org/licenses/by/ 2.0), which permits unrestricted use, distribution, and reproduction in any medium, provided the original work is properly cited.

\begin{abstract}
Introduction Mutations in the BRCA2 gene are one of the two major causes of hereditary breast cancer. Protein-truncating mutations of BRCA2 are usually deleterious and increase the risk of breast cancer up to $80 \%$ over a lifetime. A few missense mutations in BRCA2 are believed to have a similarly high penetrance, apart from more common neutral polymorphisms. It is often difficult to classify a particular sequence variant as a mutation or a polymorphism. For a deleterious variant, one would expect a greater allele frequency in breast cancer cases than in ethnic-matched controls. In contrast, neutral polymorphic variants should be equally frequent in the two groups.
\end{abstract}

Methods We genotyped 3,241 cases of breast cancer diagnosed at under 51 years of age, unselected for family history, from 18 hospitals throughout Poland and 2,791 ethnicmatched controls for a single BRCA2 C5972T variant.
Results The variant was present in approximately $6 \%$ of the Polish population. In the study, 13 women (11 cases and two controls $(\mathrm{OR}=4.7 ; p=0.02)$ ) were homozygous for the variant allele. The overall odds ratio for breast cancer in women with a single copy of the BRCA2 C5972T variant was $1.1(p=0.7)$; however, the effect was significant for patients diagnosed at or before age 40 (OR $=1.4 ; p=0.04)$. We reviewed the association between the BRCA2 variant in different histologic subgroups and found the effect most pronounced in women who had ductal carcinoma in situ (DCIS) with micro-invasion $(\mathrm{OR}=2.8 ; \mathrm{p}<0.0001)$.

Conclusion The BRCA2 C5972T allele is a common variant in Poland that increases the risk of DCIS with micro-invasion. The homozygous state is rare but increases the risk of breast cancer five-fold.

\section{Introduction}

There are several approaches to identifying low-penetrance candidate genes for breast cancer. In one approach, it is assumed that missense variants of genes for which truncating mutations are clearly pathogenic might also be deleterious. If the missense allele demonstrates high penetrance (i.e. like truncating mutations), then it will be relatively straightforward to establish the association when allele frequency is high. If the penetrance of the missense variant is low, however, then the association may be missed if only a small number of cancers is studied and the variant may falsely be classified as a neutral polymorphism. We are in the process of establishing a large database of breast cancer cases and ethnic-matched controls in order to evaluate the pathogenicity of the common founder alleles of the most important cancer susceptibility genes. Sev- eral deleterious founder alleles have been identified in $B R C A 1$, but to date, no founder mutation in BRCA2 has been identified [1-3]. There are a few common variant alleles in BRCA2 in Poland; one of these (C5972T) changes the amino acid sequence of BRCA2 from threonine to methionine at codon 1915. It lies within the range of the BRC encoded by exon 11 that are thought to be involved in binding to RAD51 [4]. We sought to determine whether this common missense BRCA2 variant plays a role in breast cancer susceptibility.

\section{Materials and methods Study subjects}

The study population included prospectively ascertained cases of invasive breast cancer diagnosed at 50 years of age or less at 18 treatment centers throughout Poland between 
1997 and 2003. Invitation to participate was delivered during hospital stay or by mail. During the interview, the goals of the study were explained, informed consent was obtained, genetic counseling was offered, and a blood sample was taken for DNA analysis. A detailed family history of cancer was taken (first-, second-, and third-degree relatives included) and a risk factor questionnaire was completed. A total of 4,778 cases of early onset invasive breast cancer were identified at the 18 participating centers during the study period. Of these, 3,627 women (76\%) accepted to participate and provided a blood sample for DNA analyses, 114 died, and 16 refused to participate. The medical record and pathology report were reviewed. In the end, we had DNA available for genotyping from 3,241 patients.

\section{Controls}

Two control groups were combined. The first group consisted of 2,000 unselected neonates from ten hospitals throughout Poland born in 2003 and 2004. Samples of cord blood were forwarded to the study center in Szczecin. The second control group consisted of 1,000 adults from the region of Szczecin unselected for cancer family history, sex, or age. We genotyped 2,791 controls for the C5972T allele, 1,993 neonates and 798 adults. To ensure comparability of the control groups, C5729T allele frequencies were computed separately for the adult and neonatal control groups and compared. The study protocol was approved by the ethics committee of the Pomeranian Medical University.

\section{Laboratory methods}

All experiments were performed at the Department of Genetics and Pathology, Pomeranian Medical University, Szczecin, Poland.

\section{DNA isolation}

DNA samples were obtained from peripheral blood of adults or from cord blood of neonates using the non-enzymatic rapid method as described previously [5].

\section{Analysis of the C5972T variant}

The C5972T variant (Thr1915Met) was analyzed by restriction fragment length polymorphism PCR using b5972F (5'-CTC TCT AGA TAA TGA TGA ATG ATG CA) and b5972R (5'CCA AAC TAA CAT CAC AAG GTG) primers. The forward primer introduces an artificial restriction site for the Mph1103I enzyme (Fermentas, St. Leon-Rot, Germany)

PCR products were digested in mutation positive cases. PCR products were separated in $3 \%$ agarose gel and visualized in ultraviolet light. For positive cases with RFLP-PCR (cleaved by Mph1103I), a DNA sample was sequenced to confirm the presence of the mutation. Additionally, 72 randomly selected samples negative with RFLP-PCR for the C5972T variant were sequenced. The results of RFLP-PCR and of direct DNA sequencing were $100 \%$ concordant.

\section{DNA sequencing}

A fragment of BRCA2 exon 11 was amplified by PCR using b5972F/b5972R primers. The purified PCR products were sequenced directly with a BigDye Terminator v3.0 DNA Sequencing Kit (Perkin Elmer, Foster City, CA, USA) and the same reverse primer used previously for the amplification of exon 11 of the BRCA2 gene. Products of sequencing reactions were separated and analysed on the ABI 377 DNA Sequencer (Perkin Elmer).

\section{BRCA1 testing}

All breast cancer patients were tested as described previously [4] for three mutations (5382insC, C61G, 4153delA) representing $80 \%$ to $90 \%$ of all high-risk BRCA1 changes in Poland.

\section{Statistical analysis}

Statistical analysis included a comparison of the prevalence of the C5972T allele in cases and controls. Odds ratios (ORs) were generated from two-by-two tables and statistical significance was assessed with the chi-square test. BRCA2 nucleotides were identified according to the GeneBank U43746 sequence.

\section{Results}

The C5972T variant was detected in $8.3 \%$ of unselected breast cancer patients diagnosed at age 40 years or below, in $5.7 \%$ of cases diagnosed from age 41 to 50 years, and in $5.8 \%$ of Polish controls. The overall OR for breast cancer with a C5972T mutation was 1.1 (95\% Cl: 0.8-1.3); however, in women less than 40 years old the OR was 1.4 (95\% Cl: $1.0-$ 1.9) (Table 1).

We found 13 C5972T homozygotes (11 patients and 2 controls). The OR associated with the homozygous state was 4.7 (95\% Cl: 1.1 to 21.4 ). Among 11 cases of breast cancer diagnosed in homozygotes, 10 were diagnosed between ages 40 and 50 years. The 11 homozygotes had predominantly intraductal (ductal carcinoma in situ (DCIS) with micro-invasion, 4 cases), ductal G3 (4 cases), lobular (2 cases), and ductal G2 (1 case) cancers. None of the first- or second-degree relatives of the homozygotes were diagnosed with breast or ovarian cancer.

We then explored the characteristics of the breast cancers that were identified in women with the BRCA2 C5972T allele (Table 2) and compared them with tumors in women without the predisposing allele (women with BRCA1 mutations were excluded from all comparisons and women who received preoperative chemotherapy were excluded from the histological comparisons). Women with the BRCA2 variant were more likely to have bilateral cancer (5\% versus $3 \%$ ) or multifocal cancer (30\% versus $23 \%$ ) but these differences were not statistically significant. However, a significant effect was observed with intraductal cancer. Among the 5972C/T 
Table 1

\begin{tabular}{|c|c|c|c|c|c|}
\hline Variant & Controls & Cases & Odds ratio & $p$-value & $95 \% \mathrm{Cl}$ \\
\hline \multicolumn{6}{|c|}{ All subjects } \\
\hline $\mathrm{CC}$ & 2,630 & 3,039 & 1.0 & & \\
\hline CT & 159 & 191 & 1.0 & 0.74 & {$[0.8-1.3]$} \\
\hline TT & 2 & 11 & 4.8 & 0.02 & {$[1.1-21.4]$} \\
\hline $\mathrm{CT}+\mathrm{TT}$ & 161 & 202 & 1.1 & 0.45 & {$[0.9-1.3]$} \\
\hline Total & 2,791 & 3,241 & & & \\
\hline \multicolumn{6}{|c|}{ Cases under age 40 years } \\
\hline $\mathrm{CC}$ & 2,630 & 598 & 1.0 & & \\
\hline CT & 159 & 51 & 1.4 & 0.04 & {$[1.0-2.0]$} \\
\hline TT & 2 & 1 & 2.2 & 0.46 & {$[0.2-23.7]$} \\
\hline $\mathrm{CT}+\mathrm{TT}$ & 161 & 52 & 1.4 & 0.03 & {$[1.0-1.9]$} \\
\hline Total & 2,791 & 650 & & & \\
\hline \multicolumn{6}{|c|}{ Cases $41+$ years } \\
\hline $\mathrm{CC}$ & 2,630 & 2,441 & 1.0 & & \\
\hline CT & 159 & 140 & 0.9 & 0.68 & {$[0.8-1.2]$} \\
\hline TT & 2 & 10 & 5.4 & 0.02 & {$[1.2-24.6]$} \\
\hline $\mathrm{CT}+\mathrm{TT}$ & 161 & 150 & 1.0 & 0.97 & {$[0.8-1.3]$} \\
\hline Total & 2,791 & 2,591 & & & \\
\hline
\end{tabular}

$\mathrm{Cl}$, confidence interval.

heterozygotes, 18 of 103 tumors were predominantly intraductal (17\%), compared to $7 \%$ in $5972 \mathrm{C} / \mathrm{C}$ breast cancer patients $(\mathrm{OR}=2.82 ; \mathrm{p} \leq 0.0001 ; 95 \% \mathrm{Cl}: 1.6-4.8)$. A heterozygous BRCA2 variant was present in $13 \%$ of the women with predominantly intraductal cancer. Compared to the population controls, the OR for intraductal cancer given a (heterozygous) form of BRCA2 variant was 2.5 ( $p=0.0005 ; 95 \% \mathrm{Cl}$ : 1.5-4.1). For women under 40 years old, the association was stronger $(\mathrm{OR}=4.1 ; \mathrm{p}=0.006 ; 95 \% \mathrm{Cl}: 1.2-8.3)$.

\section{Discussion}

The C5972T allele of the BRCA2 gene appears to be overrepresented in women with early onset breast cancer in Poland compared to controls. Although the effect was modest in the overall data set, it was stronger for women who had predominantly intraductal breast cancer and for women who were homozygous for the variant allele. Existing reports on the C5972T variant do not record any case of homozygote TT genotypes $[6,7]$. It is of interest that the heterozygote state was associated with early onset breast cancer and the homozygote state with later onset cancer (above 40 years of age). To our knowledge, this has not been seen before and there is no compelling explanation; however, we believe that the sizes of these subgroups are small and require confirmation in other studies.

Our study population consisted of DCIS cases with a microinvasive component only. To our knowledge, this is the first genetic association reported for intraductal cancer with microinvasion. Our data set did not include cases of DCIS alone and we were unable to assess the effect of the BRCA2 C5972T allele in women with predominantly invasive cancer and associated DCIS. These topics will be the focus of future studies. We did not see other pathological features that distinguished $B R C A 2$-associated tumors from tumors in non-carriers. This situation is not different from that described for BRCA2 carriers in general [8-10].

Several previous studies have shown that DCIS is a characteristic feature of cancers in BRCA2 carriers [11-14]. In the case of BRCA2-associated breast cancers, it appears that loss of heterozygosity $(\mathrm{LOH})$ occurs as a means of silencing the sec- 
Table 2

\begin{tabular}{|c|c|c|c|c|c|c|c|}
\hline & \multicolumn{2}{|c|}{$5972 \mathrm{C} / \mathrm{T}$ or TT } & \multicolumn{2}{|c|}{ Wild type } & \multirow[t]{2}{*}{$\mathrm{OR}^{\mathrm{a}}$} & \multirow[t]{2}{*}{$\mathrm{p}$-value } & \multirow[t]{2}{*}{$95 \% \mathrm{Cl}$} \\
\hline & $\mathrm{N}$ & $\%$ & $\mathrm{~N}$ & $\%$ & & & \\
\hline \multicolumn{8}{|l|}{ Histology } \\
\hline Medullary & 7 & 6 & 122 & 7 & 0.86 & 0.71 & [0.4-1.9] \\
\hline Ductal & 41 & 36 & 607 & 35 & 1.04 & 0.83 & {$[0.7-1.5]$} \\
\hline Tubular or tubulo-lobular & 3 & 3 & 104 & 6 & 0.42 & 0.13 & [0.1-1.3] \\
\hline Lobular & 22 & 19 & 364 & 21 & 0.90 & 0.70 & {$[0.5-1.5]$} \\
\hline DCIS+micro-invasion & 22 & 19 & 121 & 7 & 3.18 & $<0.0001$ & {$[1.9-5.2]$} \\
\hline Other & 19 & 17 & 416 & 24 & 0.63 & 0.09 & {$[0.4-1.0]$} \\
\hline Multifocal & 19 & 30 & 211 & 23 & 1.47 & 0.17 & {$[0.8-2.6]$} \\
\hline Bilateral & 7 & 5 & 63 & 3 & 1.71 & 0.18 & {$[0.7-3.8]$} \\
\hline $\mathrm{ER}+$ & 50 & 67 & 586 & 62 & 1.24 & 0.40 & {$[0.7-2.0]$} \\
\hline \multicolumn{8}{|l|}{ Family history $+^{b}$} \\
\hline All patients & 32 & 21 & 569 & 26 & 0.72 & 0.14 & {$[0.5-1.2]$} \\
\hline \multirow[t]{2}{*}{ Diagnosed at $<40$ years } & 4 & 10 & 97 & 24 & 0.36 & 0.06 & {$[0.1-1.1]$} \\
\hline & 0 & & 0 & & 0 & $p$-value & $95 \% \mathrm{Cl}$ \\
\hline Mean age (years) ${ }^{c}$ & 43.9 & & 44.4 & & 0.5 & 0.34 & {$[-0.5-1.5]$} \\
\hline Mean tumor size $(\mathrm{cm})^{\mathrm{c}}$ & 2.0 & & 2.1 & & 0.1 & 0.41 & {$[-0.1-0.3]$} \\
\hline
\end{tabular}

aOdds ratios (ORs) for individual variables represent the odds of being a mutation carrier for a woman with a particular characteristic, compared to all other women who did not have the characteristic. For histology the comparisons were made for one histological group to all other histologies. bFamily history+ indicates the occurrence of one or more breast or ovarian cancers among first and second degree relatives. ${ }^{\circ}$ For age and tumor size comparisons, $\mathrm{p}$-values and confidence intervals refer to the difference of means. Data were missing from the following categories and these cases were excluded from the specific calculations: histology (909 cases), multi-focality (1,774 cases); bilaterality (744 cases), estrogen receptor status $(1,746$ cases), family history ( 756 cases), family history in group diagnosed $<40$ ( 150 cases). Patients who received neo-adjuvant chemotherapy were excluded from all analyses with the exception of family history. 184 patients with $B R C A 1$ mutations were excluded from all analyses. ER+, estrogen receptor expression positive.

ond allele. In one family with a germline BRCA2 mutation, three cases of invasive breast cancer and one case of DCIS were observed [13]. $\mathrm{LOH}$ at the BRCA2 locus was demonstrated in all four cases. The authors suggest that DCIS and $\mathrm{LOH}$ in the BRCA2 locus may be common early steps in the development of invasive breast cancer in BRCA2 carriers. The $\mathrm{LOH}$ data support the concept that BRCA2 behaves as a tumor suppressor gene. In support of this hypothesis are our observations of a greater breast cancer risk in women with two inherited 5972T variants and a lower frequency of positive family history among 5972C/T heterozygotes.

In our study, we observed no association between the examined variant and increased family history. This may be explained by the modest association of the examined variant with breast cancer risk and probable recessive pattern of inheritance (the highest OR values were observed in homozygotes, all of them with negative breast cancer family history).
Actually, at least some of the $5972 \mathrm{C} / \mathrm{T}$ heterozygotes may be compound heterozygotes, with the second allele being another BRCA2 variant.

We now provide epidemiological and clinical evidence demonstrating the deleterious nature of the C5972T allele. To our knowledge, functional studies have not been performed on this variant. Few other deleterious missense variants in $B R C A 2$ have been identified.

The $\mathrm{HH}$ genotype of the non-conservative amino acid substitution polymorphism $\mathrm{N} 372 \mathrm{H}$ in the BRCA2 gene was reported to be associated with a 1.3-fold to 1.5-fold increase in the risk of both breast and ovarian cancer [15-18], but there have been negative studies as well $[19,20]$.

Our control group was drawn both from the newborns of 10 Polish cities and from the adult population in the region of Szczecin; however, the frequency of alleles was similar in the newborn (5.7\%) and adult (5.8\%) populations. There was no 
evidence that the genotype frequencies of the C5972T variants deviated from those expected from the Hardy-Weinberg equilibrium for the combined control group $(p=0.79)$ or for newborn and adult control groups $(p=0.59$ and $p=0.73$ ). There was no statistical difference in the C5972T allele frequencies in newborns recruited from the Szczecin metropolitan region compared to other Polish cities (data not shown). According to existing literature data, the frequency of the C5972T variant is similar in other populations such as North American, Austrian and Oceanian $[6,7]$.

\section{Conclusion}

The heterozygosity of the BRCA2 C5972T variant appears to be a neutral polymorphism in women above the age of 40 but may be deleterious prior to age 40 . The risk associated with this allele was modest $(\mathrm{OR}=1.4)$ in young women. Strong associations were not observed until cases were subclassified by their histological appearance or by homozygous state. It is important to confirm these observations in other populations. Large, well-controlled studies are needed to establish the full range of risks associated with other BRCA2 alleles before they can definitely be identified as neutral. Identification of breast cancer susceptibility genes that are associated with modest penetrance requires very large association studies, unless the high-risk alleles are very common.

\section{Competing interests}

The authors declare that they have no competing interests.

\section{Authors' contributions}

$B G$ designed and performed lab assays. BG and $\mathrm{JL}$ conducted data analysis and drafted the manuscript. BG, JL and $\mathrm{SN}$ contributed to interpretation of results and revision of the manuscript.

\section{Acknowledgements}

We thank Tomasz Huzarski, Tomasz Byrski, Jacek Gronwald, Olga Haus, Hanna Janiszewska, Tomasz Mierzwa, Andrzej Mackiewicz, Anna Przybyła, Katarzyna Lamperska, Malgorzata Stawicka, Dariusz Godlewski, Sylwia Grodecka-Gozdecka, Marek Bębenek, Andrzej Wojnar, Ewa Grzybowska, Wioletta Pękala, Jolanta Pamula, Stanislaw Niepsuj, Karol Gugała, Stanislaw Góźdź, Jacek Sygut, Monika Siołek, Boguslaw Musiatowicz, Michal Posmyk, Radzislaw Kordek, Maria BłasińskaMorawiec, Oscar Zambrano, Bernard Wako, Ludmila Fudali, Dariusz Surdyka, Krzysztof Urbański, Marek Szwiec, Jan Koc, Elzbieta Marczyk, Janusz Ryś Andrzej Rozmiarek, Tadeusz Dębniak, Ireneusz Dziuba, Cezary Szczylik, Agnieszka Synowiec, Wojciech Kozłowski, Piotr Wandzel, Beata Czeszyńska, and Wenancjusz Domagała for recruiting subjects and collecting clinical data. The study was supported with grant no. PBZ-54/01 from the State Committee for Scientific Research.

\section{References}

1. Górski B, Byrski T, Huzarski T, Jakubowska A, Menkiszak J, Gronwald J, Pluzanska A, Bebenek M, Fischer-Maliszewska L, Grzybowska $\mathrm{E}$, et al:: Founder mutations in the BRCA1 gene in Polish families with breast-ovarian cancer. Am J Hum Genet 2000, 66:1963-1968.

2. Górski B, Jakubowska A, Huzarski T, Byrski T, Gronwald J, Grzybowska E, Mackiewicz A, Stawicka M, Bębenek M, Sorokin D, et al:: A high proportion of founder BRCA1 mutations in Polish breast cancer families. Int J Cancer 2004, 110:683-686.

3. Górski B, Cybulski C, Huzarski T, Byrski T, Gronwald J, Jakubowska A, Stawicka M, Gozdecka-Grodecka S, Szwiec M, Urbański K, et al.: Breast cancer predisposing alleles in Poland. Breast Cancer Res Treat 2005, 92(1):19-24.

4. Bork $\mathrm{P}$, Blomberg N, Nilges M: Internal repeats in the BRCA2 protein sequece. Nature Genet 1996, 13:22-23.

5. Lahiri DK, Schnabel B: DNA isolation by rapid method from human blood samples: effects of $\mathrm{MgCl}_{2}$, EDTA, storage time, and temperature on DNA yield and quality. Biochem Genet 1993, 31:321-328.

6. Sigurdson A, Hauptmann M, Chatterjee N, Alexander B, Doody M, Rutter J, Struewing J: Kin-cohort estimates for familial breast cancer risk in relation to variants in DNA base excision repair, BRCA1 interacting and growth factor genes. BMC Cancer 2004, 4:9.

7. Wagner TM, Hirtenlehner K, Shen $P$, Moeslinger R, Muhr D, Fleischmann E, Concin H, Doeller W, Haid A, Lang AH, et al.: Global sequence diversity of BRCA2: analysis of 71 breast cancer families and 95 control individuals of worldwide populations. Hum Mol Genet 1999, 8:413-423.

8. Lakhani SR, Jacquemier J, Sloane JP, Gusterson BA, Anderson TJ, van de Vijver MJ, Farid LM, Venter D, Antoniou A, Storfer-Isser A, et al.: Multifactorial analysis of differences between sporadic breast cancers and cancers involving BRCA1 and BRCA2 mutations. J Nat/ Cancer Inst 1998, 90:1138-1145.

9. Narod SA, Foulkes WD: BRCA1 and BRCA2: 1994 and beyond. Nat Rev Cancer 2004, 4:665-676.

10. Honrado E, Benitez J, Palacios J: The pathology of hereditary breast cancer. Hered Cancer Clin Practice 2004, 2:131-138.

11. Armes JE, Egan AJ, Southey MC, Dite GS, McCredie MR, Giles GG, Hopper JL, Venter DJ: The histologic phenotypes of breast carcinoma occurring before age 40 years in women with and without BRCA1 or BRCA2 germline mutations: a populationbased study. Cancer 1998, 83:2335-2345.

12. Marcus JN, Watson $P$, Page DL, Narod SA, Tonin $P$, Lenoir GM, Serova O, Lynch HT: BRCA2 hereditary breast cancer pathophenotype. Breast Cancer Res Treat 1997, 44:275-277.

13. Thomassen M, Kruse TA, Olsen KE, Borg A, Gerdes AM: Loss of heterozygosity at BRCA2 in a ductal carcinoma in situ and three invasive breast carcinomas in a family with a germline BRCA2 mutation. Breast Cancer Res Treat 2004, 87:273-6.

14. Claus EB, Petruzella S, Matloff E, Carter D: Prevalence of BRCA1 and BRCA2 mutations in women diagnosed with ductal carcinoma in situ. $J$ Am Med Assoc 2005, 293:964-969.

15. Healey CS, Dunning AM, Teare MD, Chase D, Parker L, Burn J, Chang-Claude J, Mannermaa A, Kataja V, Huntsman DG, et al.: A common variant in BRCA2 is associated with both breast cancer risk and prenatal viability. Nat Genet 2000, 26:362-364.

16. Spurdle AB, Hopper JL, Chen X, Dite GS, Cui J, McCredie MR, Giles GG, Ellis-Steinborner S, Venter DJ, Newman B, Southey MC, Chenevix-Trench G: The BRCA2 $372 \mathrm{HH}$ genotype is associated with risk of breast cancer in Australian women under age 60 years. Cancer Epidemiol Biomarkers Prev 2002, 11:413-416.

17. Auranen A, Spurdle AB, Chen X, Lipscombe J, Purdie DM, Hopper JL, Green A, Healey CS, Redman K, Dunning AM, et al.: BRCA2 Arg372 hispolymorphism and epithelial ovarian cancer risk. Int J Cancer 2003, 103:427-430.

18. Goode EL, Ulrich CM, Potter JD: Polymorphisms in DNA repair genes and associations with cancer risk. Cancer Epidemiol Biomarkers Prev 2002, 11:1513-1530.

19. Cox DG, Hankinson SE, Hunter DJ: No association between BRCA2 N372H and breast cancer risk. Cancer Epidemiol Biomarkers Prev 2005, 14:1353-1354.

20. Wenham RM, Schildkraut JM, McLean K, Calingaert B, Bentley RC, Marks J, Berchuck A: Polymorphisms in BRCA1 and BRCA2 and risk of epithelial ovarian cancer. Clin Cancer Res 2003, 9:4396-4403. 